The INL is a

U.S. Department of Energy

National Laboratory

operated by

Battelle Energy Alliance

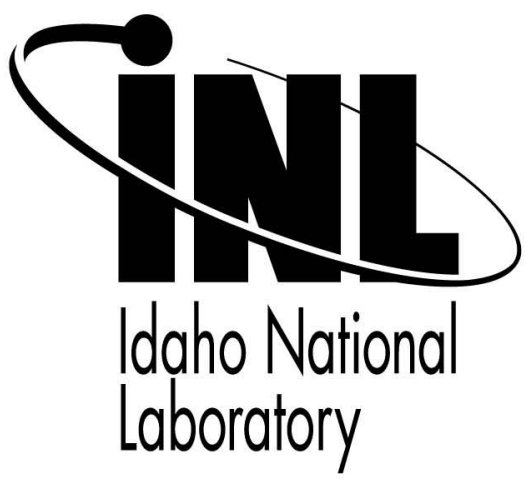

\section{Preliminary Results of an On-} Line, Multi-Spectrometer Fission Product Monitoring System to Support Advanced Gas Reactor Fuel Testing and Qualification in the Advanced Test Reactor at the Idaho National Laboratory

\section{IEEE Nuclear Science Symposium}

D. M. Scates

J. K. Hartwell

M. W. Drigert

J. B. Walter

October 2007

This is a preprint of a paper intended for publication in a journal or proceedings. Since changes may be made before publication, this preprint should not be cited or reproduced without permission of the author. This document was prepared as an account of work sponsored by an agency of the United States Government. Neither the United States Government nor any agency thereof, or any of their employees, makes any warranty, expressed or implied, or assumes any legal liability or responsibility for any third party's use, or the results of such use, of any information, apparatus, product or process disclosed in this report, or represents that its use by such third party would not infringe privately owned rights. The views expressed in this paper are not necessarily those of the United States Government or the sponsoring agency. 


\title{
Preliminary Results of an On-Line, Multi- Spectrometer Fission Product Monitoring System to Support Advanced Gas Reactor Fuel Testing and Qualification in the Advanced Test Reactor at the Idaho National Laboratory
}

\author{
D. M. Scates, J.K. Hartwell, Member, IEEE, M.W. Drigert, J.B. Walter
}

\begin{abstract}
The Advanced Gas Reactor-1 (AGR-1) experiment is the first experiment in a series of eight low-enriched uranium oxycarbide tri-isotropic (TRISO) coated particle fuel (in compact form) experiments scheduled for irradiation in the Advanced Test Reactor (ATR) located at the Idaho National Laboratory (INL). The experiment began irradiation in the ATR with a cycle that reached full power on December 26, 2006 and will continue irradiation for about 2.5 years. Six separate test fuel capsules are being irradiated in an inert sweep gas atmosphere with on-line fission product monitoring of each capsule's effluent to track fission gas emissions from the fuel during irradiation.

The online fission product monitoring system incorporates 7 HPGe spectrometers and $7 \mathrm{NaI}(\mathrm{TI})$ gross radiation detectors to monitor and quantify the fission gas releases that are important indicators of fuel performance. Details of the design and operation of this detection system and the preliminary results of the fuel performance measurements are presented in this paper.
\end{abstract}

\section{INTRODUCTION}

$\mathrm{T}$ he US Department of Energy has embarked on a series of tests of coated-particle reactor fuel intended for use as part of a future Advanced Gas Reactor (AGR) design [1]. The AGR-1 experiment is the first in a series of eight fuel tests planned for irradiation in the Advanced Test Reactor (ATR) located at the Idaho National Laboratory (INL). The AGR is based on high-temperature gas-cooled reactor (HTGR) technology. The distinguishing features of HTGRs are the use of helium coolant, a low-power-density ceramic core capable of withstanding very high temperatures, and coated-particle fuel. The AGR fuel consists of low-enriched uranium oxycarbide in tri-isotropic (TRISO) coated particles in a carbon matrix compact as shown in Fig. 1.

Manuscript received November 08, 2007.

Prepared for the U.S. Department of Energy, Assistant Secretary for Nuclear Energy, Under DOE Idaho Operations Office Contract DE-AC07-99ID13727.

All authors are with the Idaho National Laboratory, PO Box 1625, Idaho Falls, ID 83415-2114. Contact information follows:

Dawn M. Scates (telephone 208-526-5503, e-mail dawn.scates@inl.gov) John K. Hartwell (telephone 208-526-9366, email john.hartwell@inl.gov) Mark W. Drigert (telephone 208-526-1057, email mark.drigert@inl.gov) John B. Walter (telephone 208-526-0033, email john.walter@inl.gov)

\section{TRIstructural ISOtropic (TRISO) Fuel}

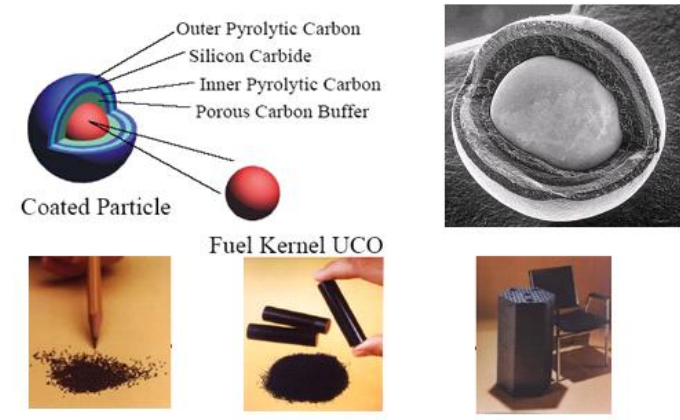

Fig. 1 TRISO Coated fuel particles (left) are formed into fuel compacts (center) and inserted into graphite block matrix (right). The coatings on the TRISO fuel form (primarily the SiC layer) provides the primary barrier to fission product release.

One important measure of the fuel performance in these irradiation experiments is quantification of the fission gas release over the course of the 2.5-year (approximately 700 Effective Full Power Days) experimental irradiation cycle, during which the fuel compacts are expected to reach a burnup of 18 atom percent [1].

The AGR-1 experiment includes six (6) individual fuel capsules, each containing twelve (12) fuel compacts arranged in 3 stacks per capsule, held in a graphite spacer, incorporated into a test train as shown in Fig. 2. The experiment is what is termed a "lead" experiment, thus the fueled section of the test train that is inserted into the ATR irradiation port connects through an umbilical cord (termed a lead-out) to systems outside the vessel. In the first experiment (AGR-1) each capsule contains about 51,000 TRISO-coated fuel particles. This experiment is intended to serve as a shakedown test of a multi-capsule design to be used in subsequent irradiations [2]. 


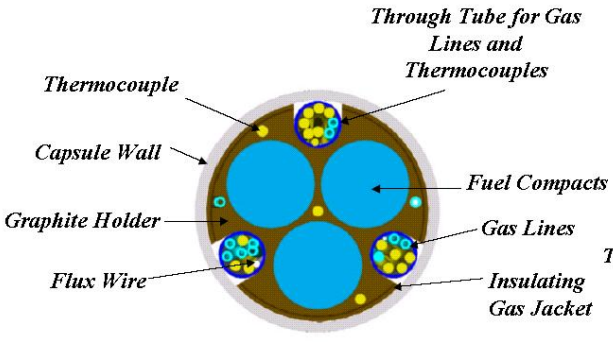

(a)

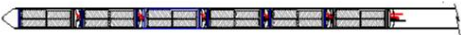

(b)
(C)

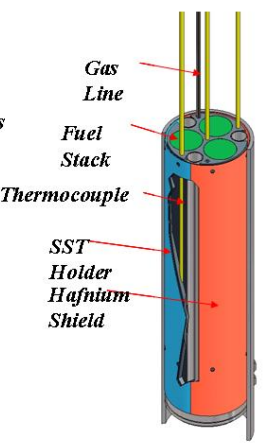

Fig. 2. Test Train and Capsule Design. Fig. (a) is a cross section of a typical capsule, Fig (b) is an example of an assembled test train and Fig. (c) is a side view of a typical capsule.

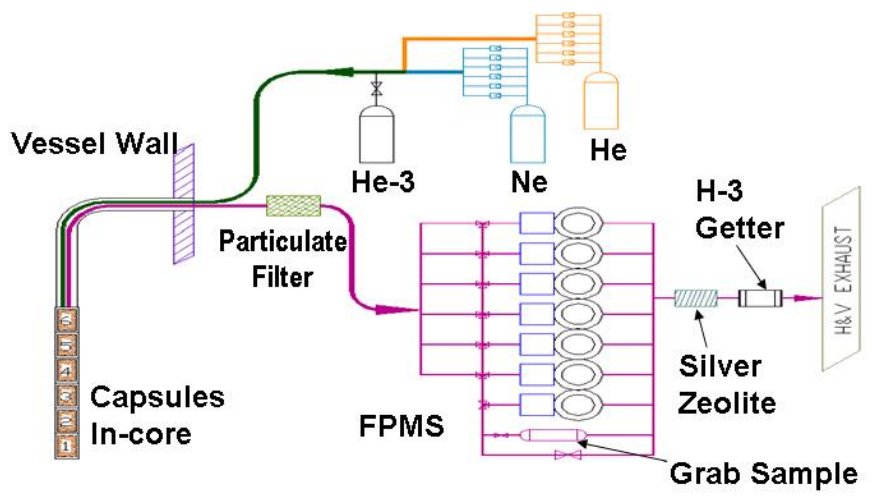

Fig. 3 AGR-1 Effluent flow and Fission Product Monitoring System (FPMS). Each of the six in-core capsules are continuously swept with inert gas during irradiation to sweep fission gasses to the FPMS.

The AGR-1 test train is located in the east large B position (B10) of the ATR core. During irradiation, independent gas lines route a mixture of inert gasses through each of the six capsules to sweep released fission products to the Fission Product Monitoring System (FPMS) which monitors each capsule's effluent in near real time [3]. Fig. 3 shows the AGR1 experiment flow path. The FPMS consists of seven (7) fission product monitors, one for each capsule plus a spare, each consisting of a heavily-shielded high-purity germanium (HPGe) gamma-ray spectrometer for energy resolution and a sodium iodide $[\mathrm{NaI}(\mathrm{Tl})]$ scintillation detector for count rate monitoring to provide indication when a "puff" release occurs [4]. The primary functions of this system are to detect the fission gas release that occurs when a TRISO fuel coating may have failed and to provide the release data to support fuel performance evaluations. The on-line analysis of the HPGe spectra provides a record of the isotopes detected in the effluent gas, the most common being inert fission gases.

\section{THE AGR-1 FPM SYSTEM}

The AGR-1 experiment began irradiation in the ATR operations cycle that reached full power on December 26, 2006 and will continue irradiation for about 2.5 years. To support this experiment, the FPMS was completely assembled, tested, and calibrated in a laboratory at the INL, and then moved and reassembled in its final location in the ATR reactor basement. Fig. 4 shows the equipment assembled in the reactor cubicle at the ATR.

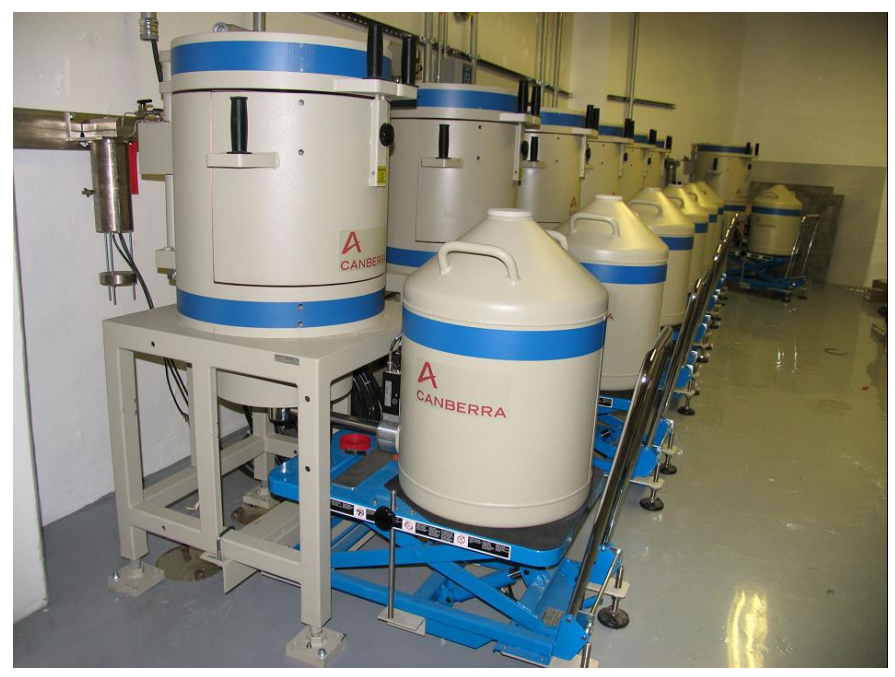

Fig. 4 AGR-1 FPM station configuration within the ATR at the INL. Each detector station contains a gross activity monitor [NaI(Tl) detector] and an HPGe Detector.

The spectrometers used for the AGR-1 experiment are LNcooled HPGe detectors. To increase the sensitivity of the spectrometer system, especially in regards to detecting the absolute quantity of fission products, the effluent gasses flow through a relatively large $\left(58 \mathrm{~cm}^{3}\right)$ gas detection chamber filled with thin baffles to thoroughly mix and slow the movement of effluent gas in front of the HPGe detector.

The gross activity monitors for the AGR-1 experiments are $\mathrm{NaI}(\mathrm{Tl})$ detectors. Each detector views a section of $3 \mathrm{~mm}$ ID effluent line just prior to its entry into the HPGe detector shield. The detector is shielded by a $25-\mathrm{mm}$ thick bismuth shield, and positioned such that it is as close to the viewed sample line segment as feasible. The viewed segment of the effluent line is defined by a specially-fabricated tungsten shield. As particle failures begin to occur, the operator can reposition the $\mathrm{NaI}(\mathrm{Tl})$ detector further from the effluent line and change the collimator size for the HPGe spectrometers.

A major requirement is that the FPMS be sufficiently sensitive to detect every individual particle failure, up to and including the first 250 failures from each capsule. Capsule fission gas releases have been modeled to simulate 250 particle failures and it is believed that the FPMS will be able to detect these failures [3]. Additional requirements are: (1) each gas effluent line must be individually monitored for fission gas activity, (2) concentrations of at least $\mathrm{Kr}-85 \mathrm{~m}, \mathrm{Kr}-$ $87, \mathrm{Kr}-88, \mathrm{Xe}-133$ and $\mathrm{Xe}-135 \mathrm{~m}$ are to be quantified for each capsule and recorded daily during irradiation, and (3) total radiation level of the sweep gas from each capsule must be recorded continuously during irradiation. 


\section{A. The Fission Product Monitoring Software}

The FPM software provides the user interface for the operation of the HPGe spectrometers and the $\mathrm{NaI}(\mathrm{Tl})$ gross activity monitors for each of the six fuel capsules and for the seventh reserve spectrometer. This interface provides the capability to modify the operation of any of these peripherals in real time. Typically, under normal operation, computerized data acquisition is continuous without operator intervention. The FPM software allows the operator to display the contents of all seven spectrometers or all seven of the gross activity monitors in near real time as is shown in fig. 5 and fig. 6 respectively. The software also allows the operator to view any single spectrum in either near real time or previously saved to disk as shown in fig. 7. The operator can similarly view the activity in a single gross activity monitor as shown in (fig. 8), where the inset is displaying saved data from a completed acquisition segment.

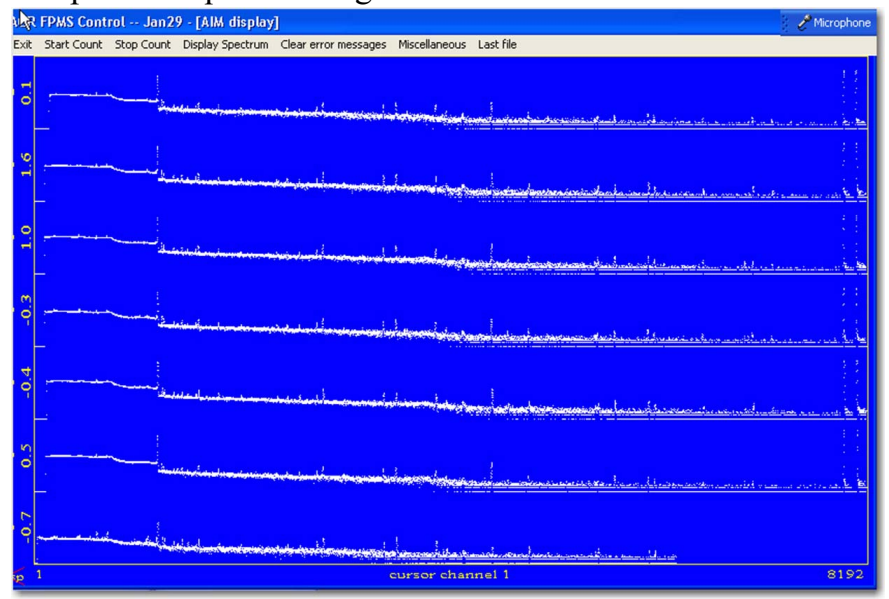

Fig. 5 The FPM Software allows the operator to look at all 7 HPGe detectors at a glance.

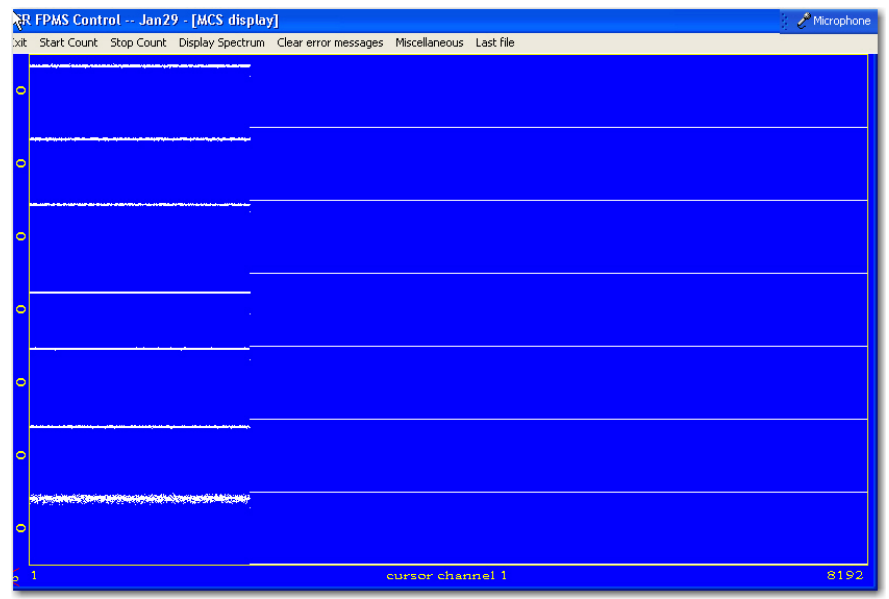

Fig. 6 The FPM software allows the operator to look at all 7 NaI(TI) gross activity monitors at a glance.

Each HPGe spectrometer and $\mathrm{NaI}(\mathrm{Tl})$ gross monitor has the ability to be placed off-line with out adversely affecting the operation of the other spectrometers. This feature is especially useful when we experience either a detector or electronic failure. The gas lines that transport the fission gas effluent from each capsule to the six FPM detector stations also has the flexibility of being able to be re-routed to the spare FPM detector station while a failed monitor is being repaired. As partially stated above, the normal operation of the monitors will be a continuous loop of collecting and then analyzing the resulting spectrum. The length of the data collection is an operator-modifiable parameter. The time range of the Multi-Channel Scaler (MCS) spectra (showing the $\mathrm{NaI}(\mathrm{Tl})$ detector count rates as a function of time) is matched to the sample measurement time used for the corresponding HPGe spectra. All spectra are stored with unique file names that identify the spectrometer as well as the time and date of the measurement.

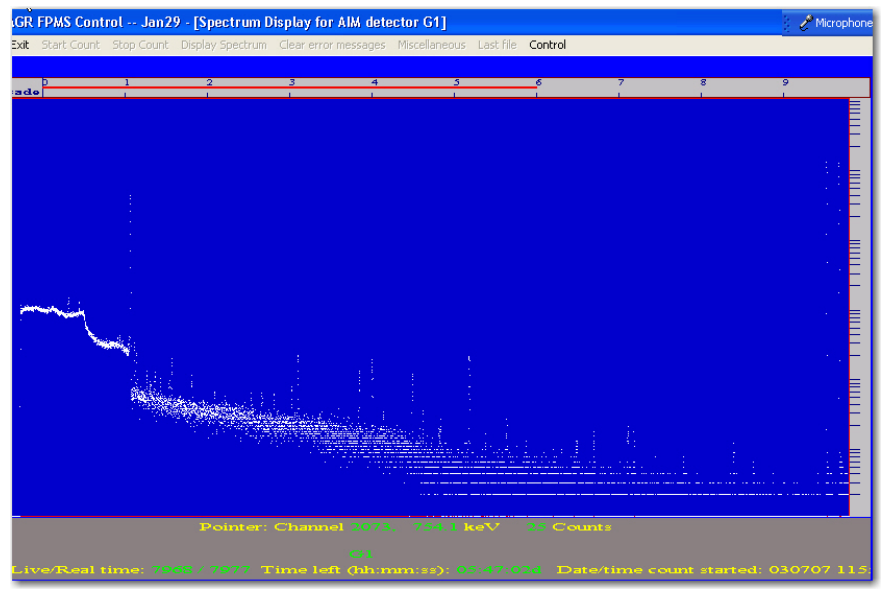

Fig. 7 The FPM allows the operator to choose to view the effluent from an individual capsule (in real-time or stored).

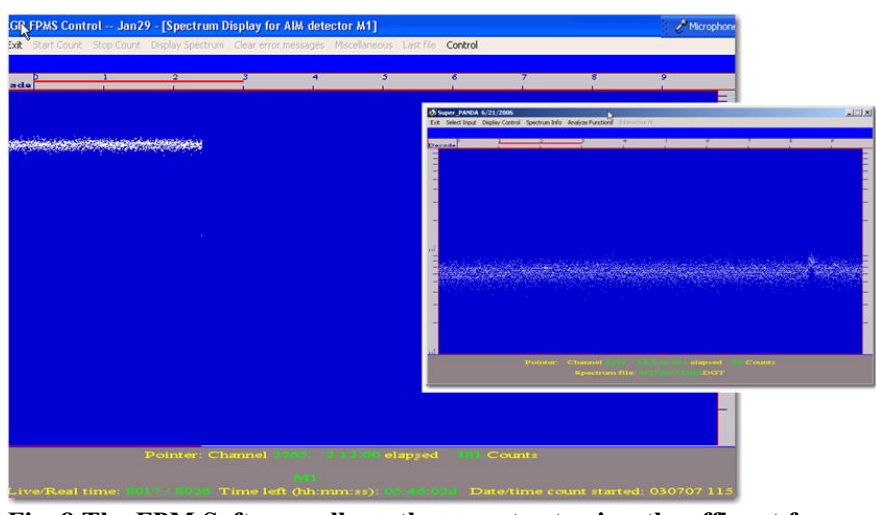

Fig. 8 The FPM Software allows the operator to view the effluent from an individual $\mathrm{NaI}(\mathrm{Tl})$ gross activity monitor in near real-time or from disk(in the inset) This feature is especially useful for viewing particle failures in near-real time. The FPMS is extremely sensitive as evidenced by the blip in the inset which was caused by changing the supply gas bottle for the sweep gas.

\section{B. Use of FPM to verify prevention of Cross Flow between the Capsules}

Because of thermal expansion differences, the individual capsules of the AGR-1 test train could not be completely sealed. A "slip" fitting was required between each capsule's bottom closure plate and tubes passing through it. This raised the possibility that under some flow conditions fission gasses from one capsule could leak to the common test train volume (called the "lead-out") and from there into a different capsule thus creating capsule-to-capsule crosstalk. To ensure no fission products leak from any capsule into the leadout, the 
leadout is supplied with helium, termed the leadout flow, at a rate such that helium leaks into each of the capsules precluding crosstalk. To determine the minimum leadout flow rate required, a leadout flow experiment was conducted in early March of 2007 while the AGR-1 test train was being irradiated. Based on pressure drop measurements made before test train installation, three of the capsules were deemed most likely to produce leakage into the leadout and result in crosstalk if the leadout flow was too low. These capsules 1, 2, and 5 were tested in turn as follows [5].

The leadout flow experiment was conducted by setting the inlet flow conditions and holding them constant for an hour to assure equilibration before making each change. Initially, the flow to the leadout and each of the capsule inlets was set to pure He at $30 \mathrm{~cm}^{3} / \mathrm{min}$ at STP (termed "sccm"). Next, the inlet flow to one of the capsules to be tested was changed to 28 sccm of $\mathrm{He}$ and $2 \mathrm{sccm}$ of $\mathrm{Ne}$. Subsequently at 1 hour intervals the He flow to the leadout was decreased by $2 \mathrm{sccm}$. This was continued, decreasing the He flow to the leadout in a step-like fashion, until the leadout flow rate was at or near zero (fig. 9). After the leadout flow had been held at its minimum for one hour, the Ne flow to the tested capsule was secured, the flow to the leadout and the capsule returned to 30 sccm $\mathrm{He}$, repeating the initial conditions, and the system maintained at that condition for 1 hour. After the 1 hour purge and wait, the process of neon injection into the inlet and sequential decreases in the flow to the leadout was repeated for the next capsule to be tested.

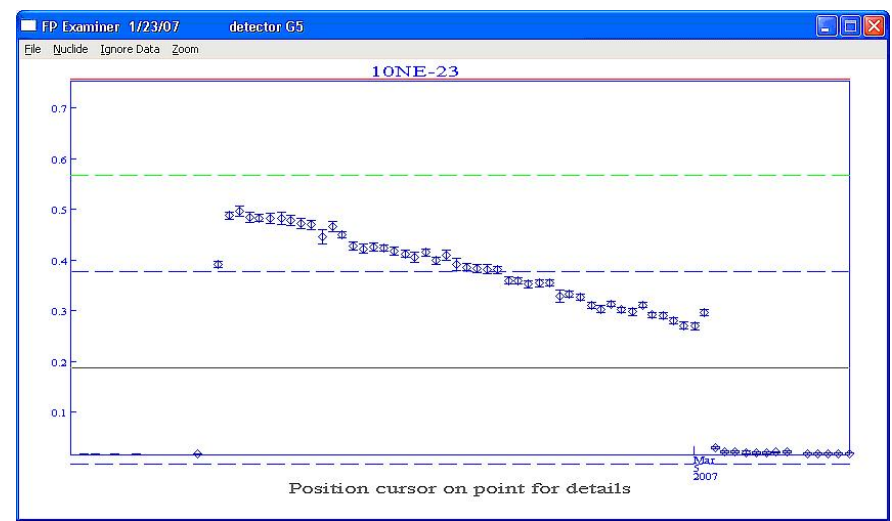

Fig. 9 Activity of ${ }^{23} \mathrm{Ne}$ (in micro-Ci per $58 \mathrm{~cm}^{3}$ ) for consecutive 20 minute spectra for the effluent from capsule 5 during the leadout flow test. The activity increases as $\mathrm{Ne}$ is introduced into the sweep gas at a fixed flow rate, and then decreases as the leadout flow is reduced hourly, decreasing the flow of He from the leadout to the capsule outlet, thus increasing the transport time from the capsule to the detector as the combined flow from the detector is reduced.

During all of these leadout flow test periods, the AGR FPMS was acquiring sequential 20 minute spectra. In the capsule under test, the dominant detected species was $23 \mathrm{Ne}$ (half life $37.24 \mathrm{sec}$ ),[1] the neutron activation product of the $22 \mathrm{Ne}$ supplied in the capsule inlet flow. To determine the lowest leadout flow that precluded effluent from the tested capsule from entering other capsules, two pieces of data were of primary importance - the presence or absence of $23 \mathrm{Ne}$ in the effluent from capsules that had no Ne supplied in their inlet stream (thus the activated Ne had to come from crosstalk with the capsule under test,) and the measured outlet flow from the tested capsule (an outlet flow rate lower than the inlet flow rate indicated losses to the leadout volume rather than inlet flow from the leadout volume) [5]. These leadout flow experiments determined that a minimum leadout flow of 16 sccm of He was required to eliminate capsule crosstalk.

\section{Testing of Transport Time with the FPM System}

In order to derive fuel performance parameters (release-tobirth ratios) the fission gas data measured at the FPMS must be corrected for decay during the transport time from the constantly-irradiated fuel capsule to the FPMS measurement location. The capsule effluent gas flow rates change according to the desired experimental conditions, therefore it is convenient to define a capsule-to-FPMS transport volume that is a function of the hardware installation. The previouslydescribed leadout flow experiment provided the additional benefit of sequentially deceasing each capsule's outlet flow rate while keeping the neon in the capsule inlet constant. This sequentially increased the transport time to the FPM Spectrometers which also increased the decay time for the short lived (37.2 second half-life) activated ${ }^{23} \mathrm{Ne}$. The relative decrease in the short-lived ${ }^{23} \mathrm{Ne}$ activity, due to decay during transport, was analyzed as a function of the measured outlet flow-rate to derive capsule-specific transport volumes for the three capsules tested (capsules 1,2,and 5) in the leadout flow experiments [5]. Transport volumes for the remaining three capsules (capsules 3,4, and 6) were estimated as the varianceweighted average of the tested capsules. The results of this analysis is presented in Table I along with the associated transport times in seconds for a nominal capsule outlet flow of $30 \mathrm{sccm}$. At nominal outlet flow rates of $30 \mathrm{sccm}$ these volume uncertainties result in $1 \sigma$ uncertainties in the capsule-todetector transport times of 3.5 to 4.5 seconds [5].

TABLE I

CAPSUle TRANSPORT Volumes FOR THE AGR-1 EXPERIMENT FROM THE CAPSULE TO THE FPM SYSTEM

\begin{tabular}{lcc}
\hline $\begin{array}{c}\text { Capsul } \\
e\end{array}$ & $\begin{array}{c}\text { Transport Volume } \\
\left(\mathrm{cm}^{3}\right)\end{array}$ & $\begin{array}{c}\text { Transport } \\
\text { Time }^{b}(\mathrm{~s})\end{array}$ \\
\hline 1 & $126 \pm 7$ & 252 \\
2 & $138 \pm 7$ & 276 \\
3 & $128 \pm 9$ & 256 \\
4 & $128 \pm 9$ & 256 \\
5 & $120 \pm 8$ & 240 \\
6 & $128 \pm 9$ & 256 \\
\hline a. & Volumes for capsules 3, 4, and 6 were determined by computing the \\
b. & variance-weighted average of the values for capsules 1,2 , and 5. \\
& Transport time in seconds at a nominal outlet flow rate of 30 sccm.
\end{tabular}

\section{Data Collection AND Fuel Performance}

\section{A. I-135 Released from AGR-1 Test Fuel}

Iodine-135 is a fission product radioiodine that decays by beta particle emission with a 6.57 hour half life. It decays to 
excited states in ${ }^{135} \mathrm{Xe}\left(\mathrm{T}_{1 / 2}=9.1\right.$ hours $)$. Among the populated states of ${ }^{135} \mathrm{Xe}$ is an isomeric state ${ }^{135 \mathrm{~m}} \mathrm{Xe}$ that decays by isomeric transition to the ${ }^{135} \mathrm{Xe}$ ground state with a half life of 15.3 minutes and the emission of a $526.6 \mathrm{keV}$ photon. The 15.3 minute isomeric state is populated through a $16.4 \%$ branch of the ${ }^{135} \mathrm{I}$ decay and is amenable to determination by gamma-ray spectroscopy using the $526.6 \mathrm{keV}$ gamma line[6].

During the AGR-1 irradiation ${ }^{135} \mathrm{Xe}$ and ${ }^{135 \mathrm{~m}} \mathrm{Xe}$ concentrations detected at the FPMS are generated both from direct fission yield and from the decay of their ${ }^{135} \mathrm{I}$ parent. However, by about 2.5 hours (ten 15.3 minute half lives) after the irradiation stops, the only source of ${ }^{135 \mathrm{~m}} \mathrm{Xe}$ is the decay of its 6.6 hour ${ }^{135} \mathrm{I}$ parent. Further, decay systematic dictate that the ${ }^{135 \mathrm{~m}} \mathrm{Xe}$ will be in secular equilibrium with its ${ }^{135} \mathrm{I}$ parent, its production rate will equal the decay rate of the parent, and its concentration in the flowing stream will appear to decay with the parent half-life [2]. This equilibrium arrangement enables determination of the amount of ${ }^{135} \mathrm{I}$ released from the fuel particles and deposited in upstream structures from quantification of the ${ }^{135 \mathrm{~m}} \mathrm{Xe}$ concentrations in the flowing gas stream following reactor shutdown [6]. The ATR operating schedule includes scheduled outages during which the reactor is shut down for a planned amount of time. Calculations of ${ }^{135} \mathrm{I}$ content from the ${ }^{135 \mathrm{~m}} \mathrm{Xe}$ activities detected just after shutdown for the first two scheduled outages determined that the activity of released I-135 for each test fuel capsule was less than 0.5 microCuries.

\section{B. AGR-1 Fuel Performance}

For intact fuel particles, the TRISO coating provides a barrier to fission product release. However, particles with failed TRISO coatings, either those that fail during irradiation or the tiny percentage of particle that are initially defective, can release fission products directly to the flowing gas stream. Because reactive fission products like the radioiodine's and cesium's quickly deposit on test train and piping structures, the only released fission products that move downstream unattenuated are the noble fission gas isotopes of $\mathrm{Kr}$ and $\mathrm{Xe}$.

One important measure of the fuel performance in these tests is quantification of the fission gas releases over the duration of each irradiation experiment. These measured released activities support the calculation of isotopic releaseto-birth ratios. Release-to-Birth ratios are used to measure fuel performance and are an accepted measurement of fuel quality [7]. The FPMS was used to acquire and analyze the fission gas isotopes of $\mathrm{Kr}$ and $\mathrm{Xe}$ as is illustrated in fig. 10 and Table II. From spectrometer data we are able to calculate the released fission gas activity. With this information along with calculated birth rates we are able to report the Release-to-Birth $(\mathrm{R} / \mathrm{B})$ ratios. We have computed average release-to-birth ratios for four different 10-day periods during the AGR-1 irradiation. Those average release-to-birth ratios for three fission gas nuclides $-{ }^{85} \mathrm{Kr},{ }^{88} \mathrm{Kr}$, and ${ }^{135} \mathrm{Xe}$ for test capsule 6 are presented in Fig. 11 as a function of irradiations exposure [effective full power days (EFPD)]. Up to now there has been no indication of a failed TRISO coating.

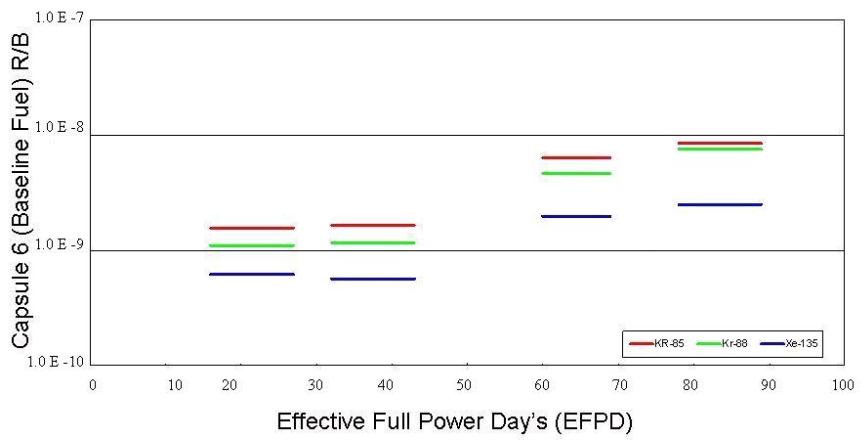

Fig. 11 Release -to-Birth Ratio's for Capsule 6 (Baseline Fuel) for Kr-85, $\mathrm{Kr}-88$ and $\mathrm{Xe-135}$. Current $\mathrm{R} / \mathrm{B}$ data is currently being evaluated up to 153 EFPD.

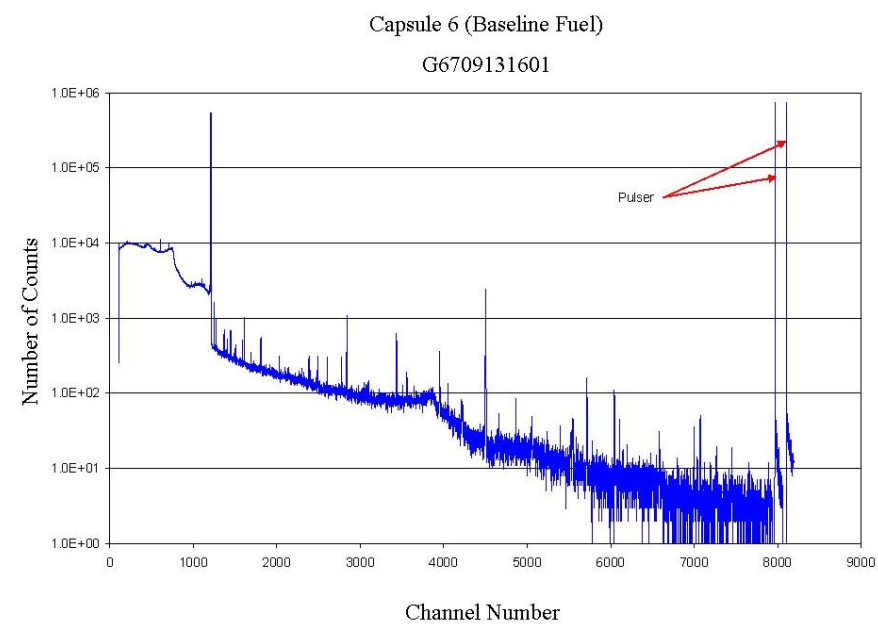

Fig. 10. A sample spectrum of inert gasses in effluent from Baseline fuel from Capsule 6. The large peak in channel 2100 is from activated ${ }^{23} \mathrm{Ne}$ in the inlet gas.

TABLE II

FisSiOn PRODUCT SUMMARY OF CAPSUle 6 SPECTRUM G6709131601

Net Micro-

\begin{tabular}{ccc} 
Isotope & Curie/58cc & Relative Error \\
\hline 36KRM-85 & $1.18 \times 10^{-3}$ & $12.72 \%$ \\
36KR-87 & $4.53 \times 10^{-3}$ & $7.11 \%$ \\
36KR-88 & $2.66 \times 10^{-3}$ & $17.28 \%$ \\
36KR-89 & $2.82 \times 10^{-2}$ & $1.89 \%$ \\
36KR-90 & $7.23 \times 10^{-4}$ & $56.03 \%$ \\
54XEM-131 & $7.58 \times 10^{-3}$ & $101.20 \%$ \\
54XE-133 & $7.55 \times 10^{-4}$ & $59.41 \%$ \\
54XE-135 & $5.15 \times 10^{-4}$ & $39.52 \%$ \\
54XEM-135 & $2.53 \times 10^{-3}$ & $4.34 \%$ \\
54XE-137 & $1.69 \times 10^{-2}$ & $2.11 \%$ \\
54XE-138 & $1.02 \times 10^{-2}$ & $6.61 \%$ \\
54XE-139 & $1.21 \mathrm{E} \times 10^{-3}$ & $20.40 \%$ \\
\hline
\end{tabular}

Table II. Concentrations are as measured at the detector uncorrected for decay during transport. 


\section{SUMMARY}

The Advanced Gas Reactor-1 Fission Product Monitor System has been designed, tested and installed at the Advanced Test Reactor located at the Idaho National Laboratory. Performance and sensitivity of the FPMS has been excellent. It is anticipated that with continued irradiation of the experiment along with continued operation of the FPMS will produce more valuable insights and lessons learned that may be applied to future AGR experiments.

The effluent activities have been analyzed to determine capsule specific fuel performance data such as isotope-specific release-to-birth ratios, and the cumulative release of radioiodines during irradiation. The acquired data indicate excellent fuel performance to date.

\section{REFERENCES}

[1] D. A. Petti, R. R. Hobbins, J. M. Kendall, and J. J. Saurwein, Editors, "Technical program plan for the advanced gas reactor fuel development and qualification program," Idaho National Laboratory, Idaho Falls, ID, Tech. Rep. INL/EXT-05-00465 Revision 1, Aug. 2005.

[2] J. T. Maki, "AGR-1 Irradiation Experiment Test Plan," Idaho National Laboratory, Idaho Falls, ID, Tech. Rep. INL/EXT-05-00593 Revision 2 March 2007.

[3] J. K. Hartwell, D. M. Scates, and M. W. Drigert, "Design of an on-line, multi-spectrometer fission product monitoring system (FPMS) to support advanced gas reactor (AGR) fuel testing and qualification in the advanced test reactor," IEEE Trans. on Nuclear Science, 54, No.3, pp. 684-689, 2007.

[4] S. B. Grover, D. A. Petti, "Initial irradiation of the first advanced gas react fuel development and qualification experiment in the advanced test reactor," Proceedings of Advanced Nuclear Fuel Cycle and SystemsGlobal 2007, Boise, ID, USA, September 2007, Idaho National Laboratory, Idaho Falls, ID, Tech.Rep. INL/CON-07-12981, Sept. 2007.

[5] J. K. Hartwell, J. B. Walter, D. M. Scates, and M. W. Drigert, "Determination of the AGR-1 capsule to FPMS spectrometer transport volumes from leadout flow test data," Idaho National Laboratory, Idaho Falls, ID, Tech. Rep. INL/EXT-07-12494, April 2007.

[6] J. K. Hartwell, D. M. Scates, J. B. Walter, and M. W. Drigert, "Determination of the quantity of ${ }^{135}$ I released from the AGR-1 test fuels at the end of ATR operating cycle 138B," Idaho National Laboratory, Idaho Falls, ID, Tech. Rep.INL/EXT-07-12455 March 2007.

[7] D.A. Petti, J. Buongiorno, J. T. Maki, R. R. Hobbins, G. K. Miller, “ Key differences in the fabrication, irradiation and high temperature accident testing of US and German TRISO-coated particle fuel, and their implications on fuel performance," Nuclear Engineering and Design, 222 (2003) 281-297. 